http://dx.doi.org/10.1590/0370-44672015710199

José Adilson de Castro

Ph.D., Professor

Universidade Federal Fluminense - UFF

Programa de Pós Graduação em Engenharia Metalúrgica

Volta Redonda - Rio de Janeiro - Brasil

joseadilsoncastro@id.uff.br

\section{Elisa Pinto Rocha}

Doutora, Professora

Universidade Federal do Rio de Janeiro - UFRJ

Departamento de Engenharia Mecânica

Campus Aloisio Teixeira

Macaé - Rio de Janeiro - Brasil

elisa_procha@yahoo.com.br

\section{Elizabeth Mendes de Oliveira}

Doutora, Professora

Centro Federal de Educação Tecnológica Celso Suckow da Fonseca - CEFET-RJ, Engenharia Metalúrgica

Angra dos Reis-Rio de Janeiro- Brasil

beth.mendes.oliveira@gmail.com

\section{Marcos Flavio Campos}

Doutor, Professor

Universidade Federal Fluminense - UFF

Escola de Engenharia Industrial Metalúrgica de Volta Redonda

Departamento de Engenharia Mecânica - VEM

Volta Redonda - Rio de Janeiro - Brasil

marcosflavio@id.uff.br

Alexandre Santos Francisco

\section{Doutor, Professor}

Universidade Federal Fluminense - UFF

Escola de Engenharia Industrial Metalúrgica

de Volta Redonda

Departamento de Engenharia Mecânica - VEM

Volta Redonda - Rio de Janeiro - Brasil

afrancisco@meta.eeimvr.uff.br

\section{Introduction}

The shaft furnace reactors are used in several industries for processing granular materials due to their flexibility, scale and economic aspects. The processes based on shaft reactors can be used for several opera-

\title{
Mathematical modeling of the shaft furnace process for producing DRI based on the multiphase theory
}

\begin{abstract}
A numerical model based on transport equations for momentum, energy and chemical species for the gas and solid phases is proposed to simulate the inner phenomena in the direct reduction of the shaft furnace process for producing directly reduced iron (DRI). The model is verified using industrial data for productivity, raw materials and final composition of the DRI product. The model is used to evaluate operational practices using new raw materials and the composition of the reducing gas in the process. Three cases were considered, which correspond to available raw materials commercialized by different suppliers. The effects on the gas and solid inner temperatures, pressure and phase composition distributions are quantified. The simulation results indicated that good agreement for overall parameters of the process could be achieved and afterwards, detailed features of the inner conditions of the process are predicted.
\end{abstract}

Keywords: DRI, multiphase theory, mathematical modeling, shaft furnace.

tion units with flexibilities for the scale of the production and raw materials used. In general, the iron direct reduction processes use a large amount of energy and raw materials, which depend particularly on the ores and pellet qualities and the shaft furnace operating conditions. Besides, depending on the reactor capacity, the charging system and the granulometric distribution of the granular materials play an important role 
on the productivity and efficiency of the process. Process modeling using advanced computers techniques have been useful for successfully analyzing the actual status and new technologies in several metallurgical reactors. Based on fundamental phenomena, the models can be used to propose new technologies able to increase the efficiency of the process and quantify their environmental impact. Direct reduction processes based on shaft furnace are widely used in the actual metallurgy industry especially for mini mill facilities. In the shaft furnace DRI process, the raw material quality is of special importance due to the guaranty of efficient heat and mass transfer in the reduction and cooling zones, in addition to the softening properties due to the steaking phenomenon. Comprehensive mathematical models could

\section{Methodology}

The methodology used in this investigation is based on the construction of a multiphase multicomponent

\subsection{Model principles}

The shaft reduction process involves complex phenomena of momentum, energy and mass transfer. Usually, the direct reduction of shaft furnace is divided into 3 zones: the reduction, transition and cooling zones. In the reduction zone, the major reactions of solid gas are mainly controlled by the heat supply and local gas composition. In the transition zone, the reducing gas is fed at temperatures around $1100{ }^{\circ} \mathrm{C}$ and the final reduction step usu- play an important role for direct reduction plant operations by demonstrating the effects of process alternatives and expediting the decision-making process, as well helping the adequate selection of raw material. The field of non-catalytic gas reaction modeling is a very active research area in chemical engineering and metallurgy process fields (Austin et al, 1997, Yagi, 1993, Castro et al 2001, 2011, 2013, Dong et al, 2014, Kuang et al, 2014). Some attempts have been made in order to develop mathematical models of the direct reduction shaft furnace (Dong et al, 2014). One of the most important applications in the industrial scale is the reduction of iron oxides. In this work, a comprehensive mathematical model for the direct reduction of iron oxides in the shaft furnace has been developed and used to simulate the steady state condition of a commercial shaft furnace for pellets and lump ore reductions. The model is used to predict the productivity and efficiency of the gas shaft furnace. The effects of all external parameters, such as the reducing gases flow rate and temperature, ore types and their characteristics, on the process behavior can be examined in order to determine the optimum operating conditions of the shaft furnace for direct reduction of pellets and lump ores in commercial plants. The model is used to study self-catalytic reforming in the transition zone. This study newly presents the simulation of the inner conditions of the shaft furnace DRI process using self-catalytic reforming in order to decrease the specific reducing gas in the process and hence decreasing the specific gas and energy consumption. tridimensional mathematical model for steady state conditions able to simulate the inner variables of the shaft furnace used to produce directly reduced iron (DRI) in a commercial scale reactor. ally takes place. A first step to construct the mathematical model is to define the computational domain and the boundary conditions representing the real reactor features. Figure 1 shows a schematic view of the shaft furnace and the constructed computational mesh used throughout the simulation carried out in this paper. The computational mesh was selected after continuous refinement of the computational grid using $1 \%$ of maximum error for

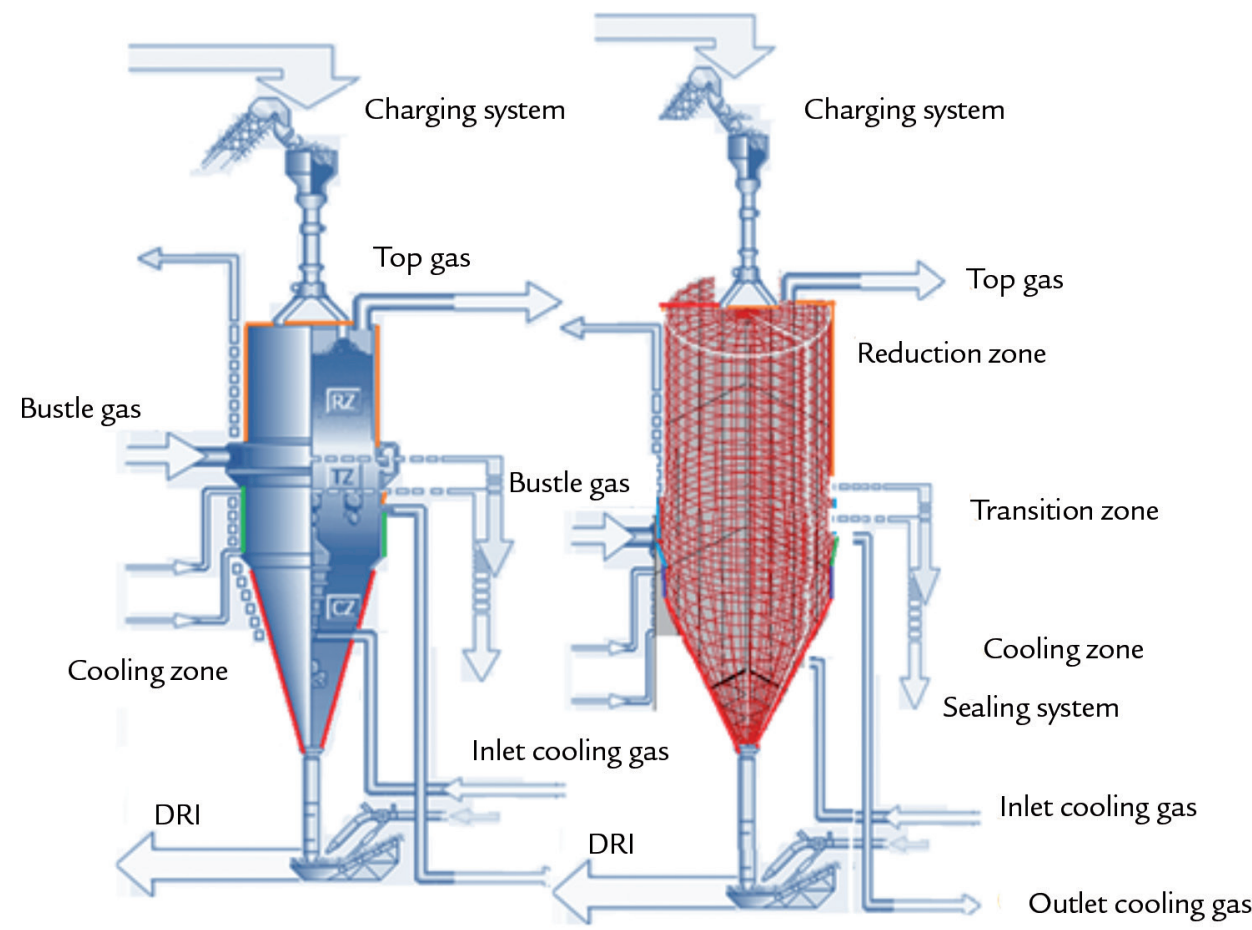

velocity, pressure and temperature fields. To successfully model the direct reduction process, detailed rate equations for the reduction steps and heat transfer mechanism are needed. In the transition zone, new opportunities for improvement on heat efficiency can be generated by using some amount of oxygen injection with partial combustion of the hydrogen releasing energy for burden heat and endothermic reactions in the reduction zone.

Figure 1

Schematic view of the shaft furnace process and the constructed computational mesh for simulating the reactor using the multiphase theory. 
For each of these phases, velocity, temperature and concentration fields are calculated while the gas phase is assumed as a continuum with a pressure field. Figure 2 shows the modeling principles for the multiphase multicomponent formulation used in this study

\subsection{Model equations}

The mathematical model is based on transport equations of momentum, energy and mass conservations. The model is formulated assuming the size for treating the packed bed composed of pellets of different diameters and lump ore with the gas flow through the arrangement of particles. The phase interactions are considered using momentum interaction for individual gas-solid packed beds and the heat transfer is computed for each individual granular material. The chemical reactions take into account the individual characteristics of the granular materials. The rate equations considered in this model can be found elsewhere (Yagi, 1993, Austin et al, 1997, Castro et al, 2011). and composition distributions for several classes of pellets with their own reduction kinetics laws. The heat transfer is considered convective and conduction simultaneously taking place within the bed structure. The general equations are presented for the solid phases classes and gas separately. (a)

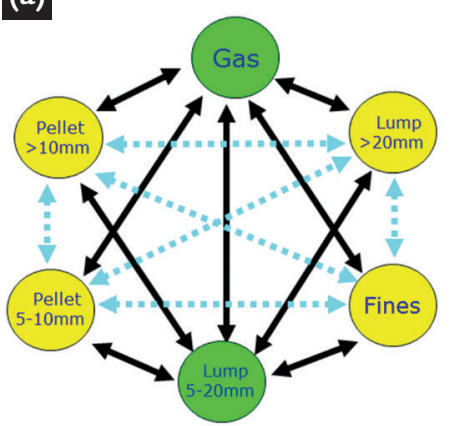

Figure 2

Multiphase and

multicomponent modeling concept applied for the packed bed composed of different classes of pellets and lump ore.

(b)

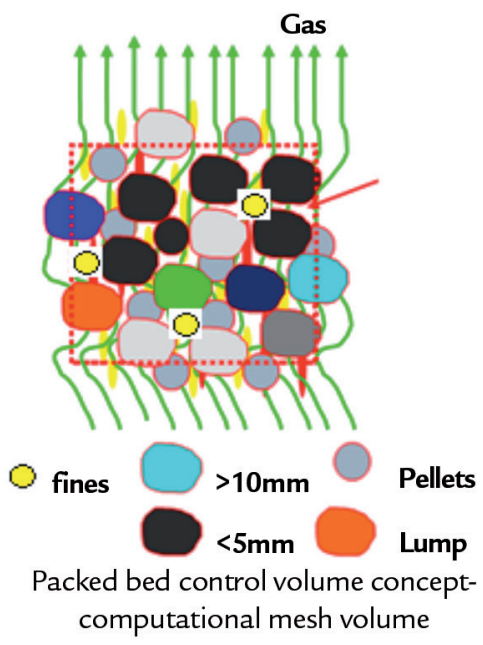

Granular classes momentum conservation:

$$
\frac{\partial\left(\rho_{i} \varepsilon_{i} u_{i, k} u_{i, j}\right)}{\partial x_{k}}=\frac{\partial}{\partial x_{k}}\left(\mu_{s} \frac{\partial u_{i, j}}{\partial x_{k}}\right)+F_{j}^{i-l}+F_{i}^{\prime}
$$

Mass conservation of solid fractions:

$$
\frac{\partial\left(\rho_{i} \varepsilon_{i} u_{i, k}\right)}{\partial x_{k}}=\sum_{m=1}^{\text {Nreacts }} M_{n} r_{m}
$$

Enthalpy balance for solid fractions:

$$
\frac{\partial\left(\rho_{i} \varepsilon_{i} u_{i, k} H_{i}\right)}{\partial x_{k}}=\frac{\partial}{\partial x_{k}}\left(\frac{k_{i}}{C_{p_{i}}} \frac{\partial H_{i}}{\partial x_{k}}\right)+E^{i-l}+\sum_{m=1}^{\text {Nreacts }} \Delta H_{m} r_{m}
$$

Chemical species of solid phases

$$
\frac{\partial\left(\rho_{i} \varepsilon_{i} u_{i, k} \phi_{n}\right)}{\partial x_{k}}=\frac{\partial}{\partial x_{k}}\left(D_{n}^{\text {eff }} \frac{\partial \phi_{n}}{\partial x_{k}}\right)-\sum_{m=1}^{N \text { reacts }} M_{n} r_{m}
$$

Gas momentum transfer:

$$
\frac{\partial\left(\rho_{g} \varepsilon_{g} u_{g, k} u_{g, j}\right)}{\partial x_{k}}=\frac{\partial}{\partial x_{k}}\left(\mu_{g} \frac{\partial u_{g, j}}{\partial x_{k}}\right)-\frac{\partial P}{\partial x_{j}}-F_{j}^{i-l}
$$


Mass conservation of the gas phase:

$$
\frac{\partial\left(\rho_{g} \varepsilon_{g} u_{g, k}\right)}{\partial x_{k}}=-\sum_{m=1}^{\text {Nreacts }} M_{n} r_{m}
$$

Enthalpy conservation of gas phase:

$$
\frac{\partial\left(\rho_{g} \varepsilon_{g} u_{g, k} H_{g}\right)}{\partial x_{k}}=\frac{\partial}{\partial x_{k}}\left(\frac{k_{g}}{C_{p_{g}}} \frac{\partial H_{g}}{\partial x_{k}}\right)-E^{g-p}-\sum_{m=1}^{N \text { reacts }} \Delta H_{m} r_{m}
$$

Chemical species

$$
\frac{\partial\left(\rho_{g} \varepsilon_{g} u_{g, k} \phi_{n}\right)}{\partial x_{k}}=\frac{\partial}{\partial x_{k}}\left(D_{n}^{e f f} \frac{\partial \phi_{n}}{\partial x_{k}}\right)+\sum_{m=1}^{\text {Nreacts }} M_{n} r_{m}
$$

Semi empirical relations for the gas solid momentum transfer:

$$
F_{j}^{g-i}=\left[1.75 \rho_{g}+\frac{150 \mu_{g}}{\left|U_{g}-U_{i}\right|}\left(\frac{\varepsilon_{i}}{d_{i} \varphi_{i}}\right)\right]\left(\frac{\varepsilon_{i}}{\left(1-\varepsilon_{i}\right)^{3} d_{i} \varphi_{i}}\right)\left|U_{g}-U_{i}\right|\left(u_{g, j}-u_{i, j}\right)
$$

Effective energy transfer among solid phases and gas:

$$
\begin{gathered}
E^{g-i}=\frac{6 \varepsilon_{i}}{d_{i} \varphi_{i}} \frac{k_{g}}{\left(d_{i} \varphi_{i}\right)}\left[2+0.39\left(\frac{\rho\left|U_{g}\right|}{\mu_{g}}\left(d_{i} \varphi_{i}\right)\right)^{1 / 2}\left(\frac{\mu_{g} C_{p, g}}{k_{g}}\right)^{1 / 3}\right]\left(T_{g}-T_{i}\right) \\
\varepsilon_{g}=1-\sum \varepsilon_{i}
\end{gathered}
$$

Where $\varepsilon_{\mathrm{i}}$ stands for the individual solid volume fractions of the pellets classes and $\varepsilon_{g}$ is the gas volume fraction, $k$ is the thermal conductivity $\mathrm{di}$ is the average particle diameter of the pellet class. The index i represents the classes of the pellets considered in the solid charged. The indexes $\mathrm{j}$ and $\mathrm{k}$ are for coordinates component direction $\mathrm{n}$ is chemical species and $m$ the indicator of the reactions, $M$ is the molecular weight of the species, $\mathrm{P}$ is gas pressure, $\mathrm{F}$ is the

\subsection{Numerical method}

The set of differential equations, Eqs. (1)-(9) are discretized using the finite volume method. The gas velocity and pressure field coupling are solved using the SIMPLE algorithm (Mealaen, 1992). For all equations, the discretized algebraic equations are determined using the power law scheme (Mealaen, 1992). The system of algebraic equations were solved using component of momentum interactions among the phases and $r$ is the rate of chemical reactions. $\rho, \varepsilon, C p, k$ and $\Delta \mathrm{H}$ are phase density, volume fractions, heat capacity, heat conductivity and heat due to chemical reactions, respectively. $T$ and $U$ are the phase temperature and velocity fields, respectively. The quantity $E^{i-l}$ is the heat transfer among the phases and accounts for convective and radiation heat transfer. The gas-solids momentum interactions are

the line-by-line iterative procedure based on the tri-diagonal algorithm. The convergence criterion assumed a maximum error of $10^{-5}$ for the momentum and energy equations, in addition to a mass balance of the individual species of less than $1 \%$. The numerical grid was selected by continuous refinement until the average error reached less than $1 \%$. The solution represented by $\mathrm{F}^{i-l}$ for each coordinate direction, given in Eq. (10). The above equations coupled with the rate of chemical reactions of reduction based on the 3-interface model for $\mathrm{H}_{2}$ and $\mathrm{CO}$ (Castro et al, 2001, 2011) and the rate equations for self-reforming reactions are solved simultaneously. In the cooling zone, the carburization of the DRI is considered as a first order reaction controlled by the carbon deposition from the methane.

algorithm uses the iterative sequence of updating all properties and interphase interactions of momentum, mass and energy by calculating all the source terms based on the actual variables, thus solving the momentum, chemical species and energy for all phases and updating all variables. Repeat this procedure until convergence of all variables is achieved. 


\section{Results and discussions}

The numerical results are presented comparing the use of 3 pellets with similar geometalurgical characteristics and distinguished size distributions. Figure 3 shows the size distributions for pellets A, B and C. Pellet $A$ is a typical raw material used in the shaft furnace. Pellets B and C are obtained by controlling the green pellet formation and sieving after firing. Figure 4 shows the gas flow and temperature distributions for

Figure 3

Granulometric fractions distributions for the comparison of 3 pellets with similar geometallurgy characteristics.

The gas flow rates at the inlet are imposed as boundary conditions and the outlet mass flow rate was compared with

Figure 4

Gas flow characteristics and temperature distributions for the operation with $90 \%$ pellet $A$ and $10 \%$ lump ore.

Actual shaft furnace operational conditions - Reference case for the simulations.

Figure 5

Gas flow characteristics and temperature distributions for the operation with $90 \%$ pellet B and $10 \%$ lump ore- Same operational conditions for the reference case. the reference operation with pellet A. The inner temperature condition and the average gas composition at the outlet agreed with the industrial data within a $2 \%$ of average error. The productivity and mass flow rates of solid materials are in agreement with the industrial data within $1 \%$. Figures 4, 5 and 6 comparatively show the gas flow rates and temperature distributions for the size distributions presented in Figures 3 (a), (b) and (c),
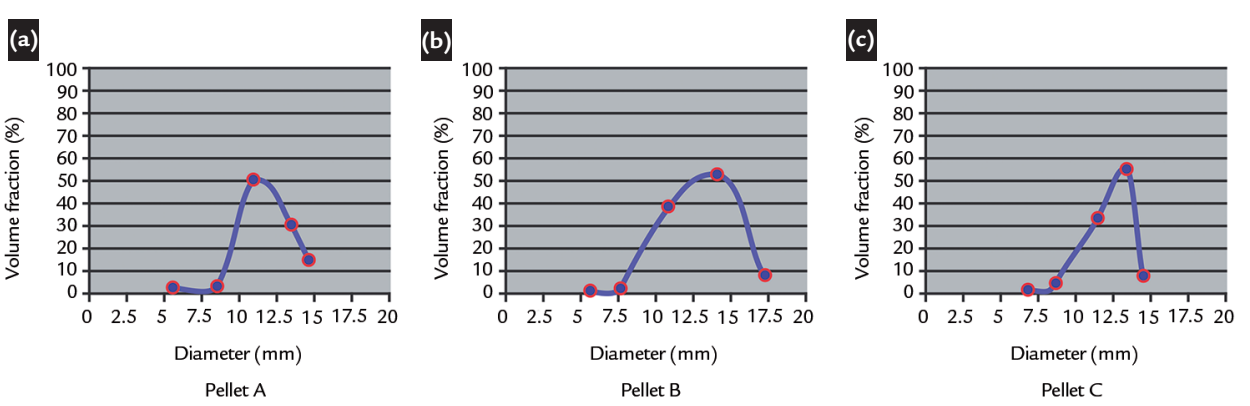

the measured one with agreement discrepancy of less than $5 \%$. This discrepancy is explained due to the complex reactions and

rate equations taking into account the local variables, which are measured under conditions that simulate the process parameters. respectively. As can be observed, the inner temperature of the central region of the reactor decreased for the distributions shown in Figures 3 (b) and (c). The reason for such behavior is mainly due to the changes in the gas flow rates. It is worthy to mention that the metallization was aimed constant and the solid inflow was adjusted, which promotes inner temperature and gas flow changes, as evidenced in Figures. 4, 5 and 6.
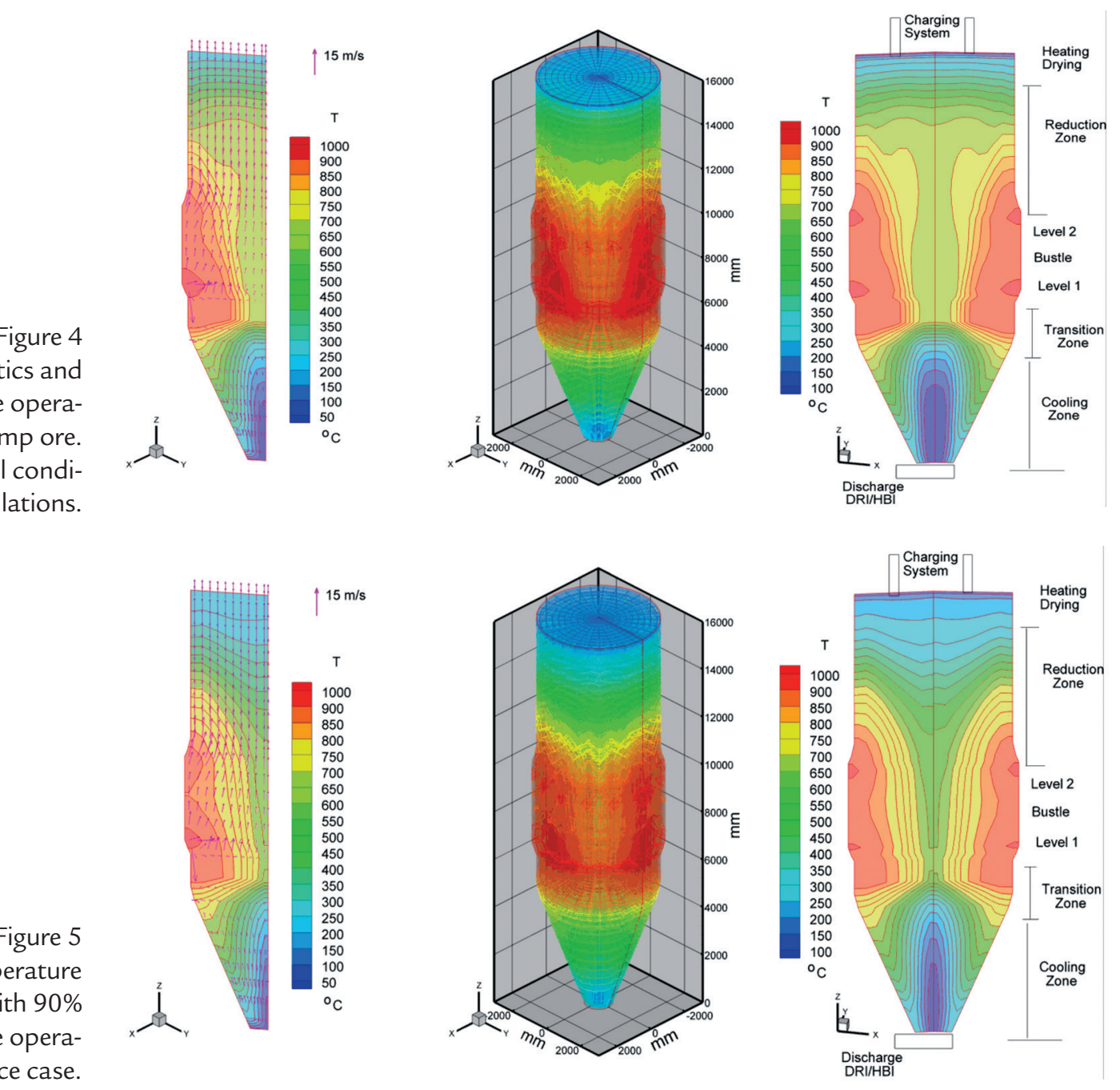

REM, Int. Eng. J., Ouro Preto, 71(1), 81-87, jan. mar. | 2018 
Figures 5 and 6 show the inner variables for pellets $B$ and $C$, respectively. As can be observed, when the granulometric distribution is narrowed, the temperature profile moves upward. The reason for this behavior is attrib-
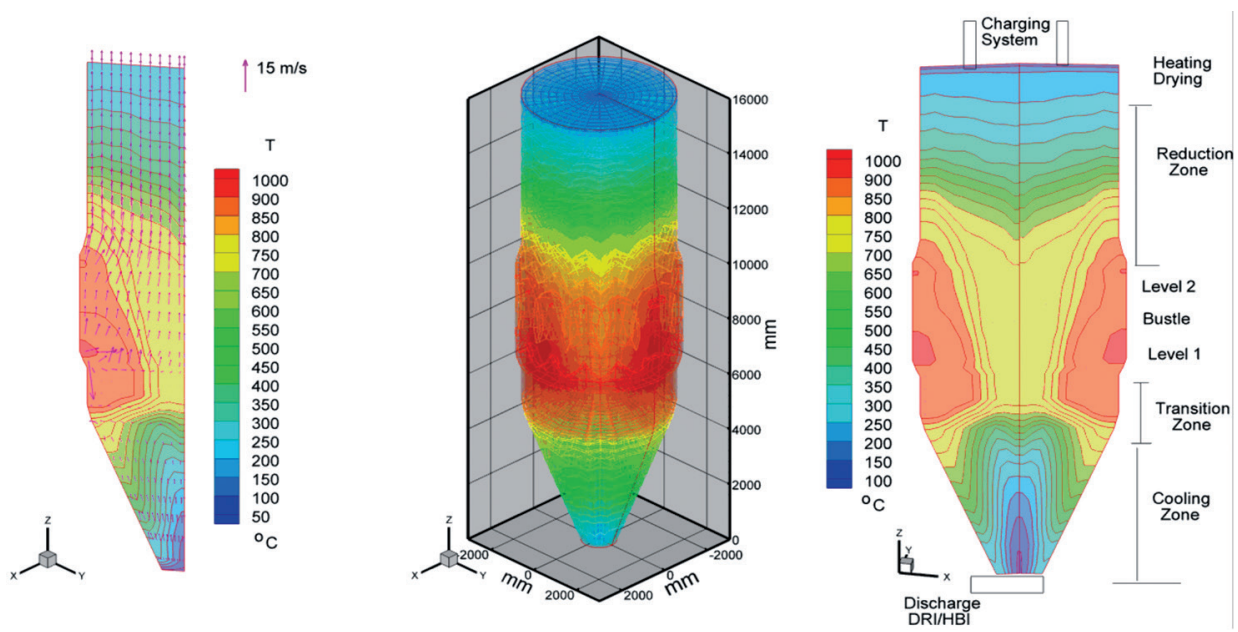

Figure 7 shows the self-catalytic effect by adding $\mathrm{CH}_{4}$ and $\mathrm{O}_{2}$ in the bustle
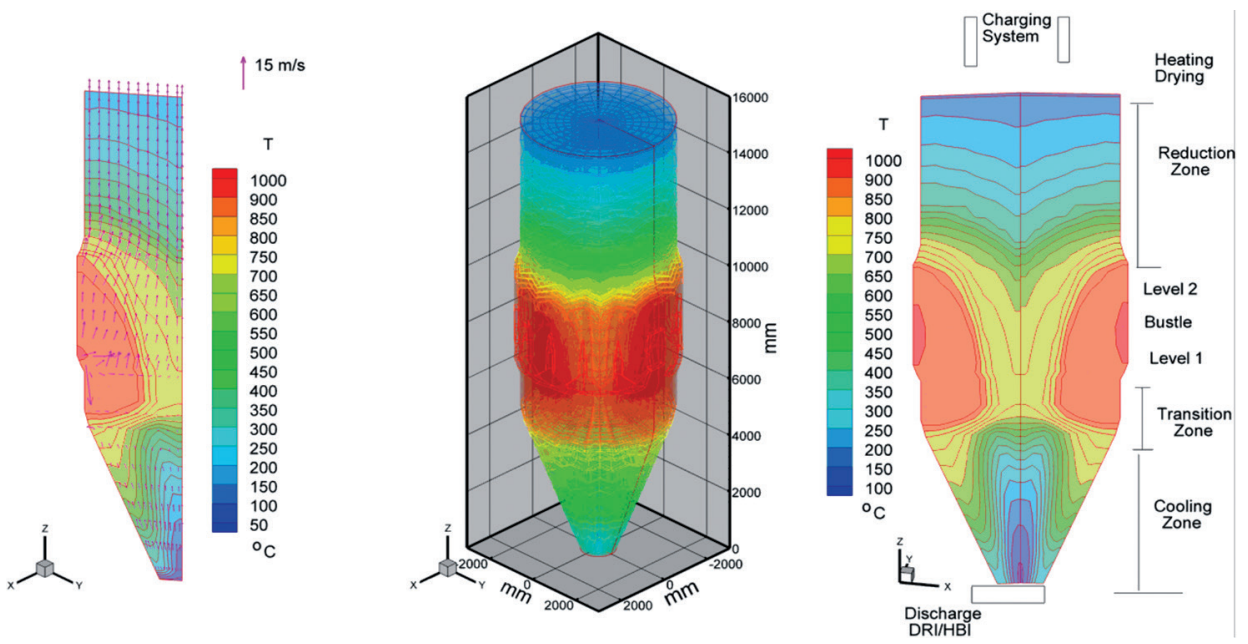

This technology can be used with restriction due to the possibility of excessively increasing the temperature and hence allowing the clustering phenomena. However, as can be observed in Fig. 7, the temperature distribution in the reduction

\section{Conclusions}

This paper analyzed the shaft furnace for direct reduction as a multiphase multicomponent momentum, energy and mass transfer reactor by applying a comprehensive mathematical model. zone which promotes reactions of gas reforming and post combustion of $\mathrm{H}_{2}$,
The effect of process variables and raw materials were investigated. The model indicated that further improvements on the energy efficiency and environmental benefits could be obtained by using self- uted to the enhanced heat and mass transfer due to more uniformity of the gas flow.

Figure 6

Gas flow characteristics and temperature distributions for the operation with 90\% pellet $C$ and $10 \%$ of lump ore - Same operational conditions for the reference case.

CO which supply heat for enhancing the reduction zone temperature.

Figure 7

Effect of the self-catalytic reactions (1.8\% $\mathrm{CH}_{4}$ and $1.5 \% \mathrm{O}_{2}$ added to flow rate).

catalytic effect is mainly obtained with the reduced iron in the transition zone of the reactor acting as an activated surface for the $\mathrm{CH}_{4}$ reforming reactions and the partial combustion furnishes additional energy for the reforming reactions. catalytic reactions and compensation of the heat supply using partial combustion of natural gas with oxygen up to $1.5 \%$ on the reducing gas inlet for the same metallization of the DRI product.

\section{References}

AUSTIN, P. R., NOGAMI, H., YAGI, J. A mathematical model for blast furnace reaction analysis based on the four fluid model. ISIJ International, v. 37, n. 8, p. 748-755, 1997.

CASTRO, J. A., NOGAMI, H., YAGI, J. Numerical analysis of multiple injection of pulverized coal, prereduced iron ore and flux with oxygen enrichment to the 
blast furnace. ISIJ International, v. 41, n. 1, p. 18-24, 2001.

CASTRO, J. A., SILVA, A. J., SAZAKI, Y., YAGI, J. A six-phases 3-D model to study simultaneous injection of high rates of pulverized coal and charcoal into the blast furnace with oxygen enrichment. ISIJ International, v. 51, n.7, p. 748-758, 2011.

DONG FU, YAN CHEN, YONGFU ZHAO, D'ALESSIO, J., FERRON, K. J., CHENN Q. ZHOU. CFD modeling of multiphase reacting flow in blast furnace shaft with layered burden. Applied thermal Engineering, v. 66, n. 1-2, p. 298-308, 2014.

KUANG, S. B., LI, Z. Y., YAN, D. L. QI, Y. H., YU, A. B. Numerical study of hot charge operation in ironmaking blast furnace. Minerals Engineering, v. 63, p. 45-56, 2014.

MELAEN, M. C. Calculation of fluid flows with staggered and nonstaggered curvelinear nonorthogonal grids-the theory. Numerical Heat Transfer B, v. 21, n.1, p.1-19, 1992.

YAGI, J. Mathematical modeling of the flow of four fluids in a packed bed. ISIJ International, v. 33, n. 6, p. 619-639, 1993.

Received: 23 December 2015 - Accepted: 11 May 2016. 